\title{
Optimizing Practice Through Research: A New Perspective to Solve an Old Problem
}

Thomas E. Kottke, $M D, M S P H^{1}$
Leif I. Solberg, $M D^{1}$
Andrew F. Nelson, $M P H^{1}$
Donald W. Belcher, $M D^{2}$
William Caplan, $M D^{3}$
Lawrence W. Green, $\mathrm{Dr}^{4} \mathrm{H}^{4}$
Eva Lydick, PbD
David J. Magid, MD
Sharon J. Rolnick, $P b D, M P H^{1}$
Steven H. Woolf, $M D, M P H^{7}$
'HealthPartners Research Foundation,
Minneapolis, Minnesota
${ }^{2}$ Department of Medicine (Emeritus),
University of Washington, Seattle
${ }^{3}$ Kaiser Permanente's Care Management Institute, Oakland, California

${ }^{4}$ Department of Epidemiology and Biostatistics, and Comprehensive Cancer Center University of California at San Francisco

${ }^{5}$ Lovelace Clinic Foundation, Albuquerque, New Mexico

${ }^{6}$ Kaiser Permanente Colorado Clinical Research Unit, Departments of Emergency Medicine, and Preventive Medicine and Biometrics, University of Colorado Health Sciences Center, Denver

${ }^{7}$ Departments of Family Medicine, Epidemiology, and Community Health, Virginia Commonwealth University, Richmond

Conflicts of interest: Drs Woolf and Green bave declared that their academic institutions receive funding from federal agencies and foundations to conduct research and to operate practice-based research networks and CTSAs to address the research needs discussed in this article. No other author has a potential conflict of interest with the material presented.

\section{CORRESPONDING AUTHOR}

Thomas E. Kottke, MD, MSPH HealthPartners Research Foundation 8170 33rd Ave S

PO Box 1524, MS 21111R

Minneapolis, MN 55440-1524

thomas.e.kottke@healthpartners.com

\begin{abstract}
Policy makers, researchers, clinicians, and the public are frustrated that research in the health sciences has not resulted in a greater improvement in patient outcomes. Our experience as clinicians and researchers suggests that this frustration could be reduced if health sciences research were directed by 5 broad principles: (1) the needs of patients and populations determine the research agenda; (2) the research agenda addresses contextual and implementation issues, including the development of delivery and accountability systems; (3) the research agenda determines the research methods rather than methods determines the research agenda; (4) researchers and clinicians collaborate to define the research agenda, allocate resources, and implement findings; and (5) the level of funding for implementation research is commensurate with and proportional to the magnitude of the task. To keep the research agenda focused on the task of improving health and to acknowledge that the effort must be seen as more comprehensive than translating or transferring research into practice (TRIP), we suggest that the task be reframed, using the term optimizing practice through research.
\end{abstract}

Ann Fam Med 2008;6:459-462. DOI: 10.1370/afm.862.

\section{INTRODUCTION}

$\mathrm{P}$ olicy leaders are frustrated that recent discoveries in the health sciences have not been incorporated rapidly and completely into clinical or community practice. ${ }^{1}$ This frustration has led to the creation of the NIH Roadmap ${ }^{2}$ and Clinical and Translational Science Awards (CTSAs). ${ }^{3}$ Although the task of improving quality through innovation in the delivery of health services is frequently described as "translating research into practice," or TRIP, ${ }^{4}$ our experience as researchers and clinicians leads us to believe that conceptualizing the task in this way fails to describe the process that must be set in motion if research is to improve the health status of patients and populations. It also places undue emphasis on only one component of the mission of research in the health sciences, "pursuit of fundamental knowledge about the nature and behavior of living systems." ${ }^{15}$ To retain the focus of health sciences research on its ultimate mission, "to extend healthy life and reduce the burdens of illness and disability," we suggest that the task be reframed, using the term optimizing practice through research, and we suggest that the task of improving health outcomes through research be based on 5 broad principles.

\section{IMPROVING HEALTH OUTCOMES THROUGH RESEARCH Principle 1. Needs of Patients and Populations Determine the Research Agenda}

Before the development of highly sophisticated basic sciences, the health sciences research agenda was defined by the problems that clinicians faced 
in their daily practices. Today, there are indications that the research agenda is defined with little apparent regard for clinical or population epidemiology. ${ }^{6}$ Claude Lenfant, the former director of the National Heart, Lung, and Blood Institute, expressed his concern about this trend in his Shattuck Lecture, when he wrote that science must answer the question, "Are the results [of research] likely to be applied in a clinical setting?"7

Research in heart disease illustrates the importance of asking this question. Heart disease, the leading cause of death in the United States ${ }^{8}$ has both genetic and behavioral causes. Hypertrophic cardiomyopathy, the leading cause of death from heart disease among young athletes, is caused by missense gene mutations. ${ }^{9}$ Developing a successful gene identification and therapy program might allow athletes with this genetic disease to live longer and continue in competition. Eradicating the disease, however, could lower population death rates only by the prevalence rate of the disease, $0.2 \% .{ }^{9}$

By contrast, effective lifestyle programs focused on a healthful diet, abstinence from tobacco, adequate physical activity, and moderate alcohol consumption could benefit up to $95 \%$ of persons in typical US populations. ${ }^{10-12}$ With better adherence to these 4 lifestyles, it is possible that life expectancy could be extended by up to 14 years, ${ }_{1}^{13}$ and nearly two-thirds of coronary heart disease events might be prevented. ${ }^{14}$

Changes of this magnitude should not be considered impossible. Associated with a sustained chronic disease prevention program and improved health service delivery, death rates from coronary heart disease fell by $82 \%$ in Eastern Finland. ${ }^{15}$ Changes in risk factor levels were responsible for up to $73 \%$ of the decline through $1997 .{ }^{16}$

Although effective behavioral interventions to address the lifestyle causes of heart disease can be applied to $95 \%$ of a practitioner's patients, therapies for hypertrophic cardiomyopathy are not applicable to $99 \%$. Society may decide that it is appropriate to devote resources to develop treatments that can only be applied to a few, but the goal of improving the health of the many can be accomplished only by addressing the common causes of common diseases.

\section{Principle 2. Research Agenda Addresses Contextual and Implementation Issues, Including Development of Delivery and Accountability Systems}

Failure to adopt health sciences innovations can be due to the lack of intervention and accountability systems. Two 19th century innovations are illustrative: systems to maintain a sterile operating field, and the morbidity and mortality conference. ${ }^{17}$ Surgeons made little progress in improving outcomes until systems to maintain asepsis were developed. Even after it was shown that these systems were the key to improved surgical outcomes, they did not become the standard until the morbidity and mortality conference made surgeons accountable for their outcomes. ${ }^{17} \mathrm{~A}$ more contemporary example is systems research that has demonstrated the efficacy of protocols to reduce infections from venous and arterial catheters. ${ }^{18}$

As chronic diseases have emerged as a management challenge for 21 st century care systems, the importance of care management and accountability systems has become apparent. ${ }^{19,20}$ Although the potential contribution of systems science is increasingly appreciated, more research is needed to understand how to improve care delivery systems. ${ }^{21}$

\section{Principle 3. Research Agenda Determines the Research Methods Rather Than Methods Determine the Research Agenda}

It has been observed that research is often driven by topics which are considered researchable rather than by the needs of the end user. ${ }^{22}$ Although other research methods-for example, interrupted time series analysis-are more appropriate for some tasks, best-quality evidence is frequently still defined as the results of a randomized trial. Improved outcomes resulting from improved practice require that (1) the scope of research is defined by the questions which must be addressed and (2) a much broader range of investigative methods be used. These methods include epidemiologic observations, clinical observations, quasi-experimental evaluations of natural experiments, time series experiments, case studies of apparently successful projects or organizations, rapid-cycle learning, and qualitative studies, either alone or as mixed methods studies in combination with quantitative studies. ${ }^{23}$ When addressing certain issues, these designs can often produce more pertinent results without the expense and delay that conventional randomized trials require.

A preventive services improvement initiative illustrates how the agenda should be used to drive the research methods rather than vice versa. Working in their fee-for-service ambulatory care network, the Baylor Health System quality improvement group set a goal of improving patient outcomes by increasing the delivery of the preventive services recommended by the United States Preventive Services Task Force. To change the care delivery system, the group rapidly implemented 11 interventions that had been tested in clinical trials. Making no particular effort to determine whether one intervention generated more impact than any other, the Baylor group continuously monitored their progress and documented that the proportion of services "recommended or done" rose from $68 \%$ in 2000 to $92 \%$ in 2006. During the period from 2001 to 2006, the group 
increased the proportion of services that were "done" from $70 \%$ to $86 \%$, and they increased the proportion of patients who received "perfect care" from 19\% to 51\%. Their intervention strategy can be described as the application of an ensemble of multiple efficacious system development tools to increase delivery of efficacious patient-level interventions, and their evaluation design was pre-post tracking of objective performance data. ${ }^{24}$

\section{Principle 4. Researchers and Clinicians} Collaborate to Define the Research Agenda, Allocate Resources, and Implement Findings

At more than 100 practice-based research networks (PBRNs) in the United States, researchers and clinicians collaborate to conduct care improvement studies in the outpatient setting. ${ }^{25,26}$ Similarly, the Centers for Disease Control and Prevention supports a network of prevention research centers mandated to engage their community agencies, practitioners, and populations in participatory research planning, execution, and interpretation. ${ }^{27}$ The National Institutes of Health Roadmap and its CTSA program also give some recognition to the potential contribution of practitioners and PBRNs to promote science and seek to involve them in the task of translating research into practice. ${ }^{2,3}$ Collaborative efforts of researchers and practitioners in other fields have been shown to increase the adoption of innovations. ${ }^{28}$

Although the dividing line between conventional quality improvement programs and scholarly research to improve quality can be ill-defined, ${ }^{29}$ important research efforts to improve quality occur in that nexus. For example, the Veterans Health Administration Quality Enhancement Research Initiative (QUERI) program has been cited as a successful model of collaboration. ${ }^{30}$ This data-driven approach to quality improvement has resulted in improved influenza and pneumococcal vaccination rates, increased collaborative care for depression, computerized decision support for treating hypertension, improved diabetes care, prompt revascularization for patients with acute coronary syndromes, and increased colorectal cancer screening rates. ${ }^{31,32}$ The leadership of the QUERI program has identified 4 processes that they consider critical to the success of their program: (1) research is linked to the needs of patients and system performance, (2) implementation is studied systematically, (3) researchers and policy makers interact directly, and (4) activities are both topdown and bottom-up (ie, generated by both research directors and front-line clinicians).

Other organizations have also recognized the value of end-user participation in developing the research agenda. For example, the Canadian Health Services Research Foundation program-Research, Exchange
\& Impact for System Support (REISS)—requires 4 components in the programs it supports: original research, a capacity-development activity (to conduct, disseminate or use research), knowledge transfer and exchange activities, and system-relevant program deliverables. ${ }^{33}$ The program requires both matching funds from cosponsoring organizations and the formation of interdisciplinary teams that include researchers and decision makers from relevant organizations.

To focus research on population and clinical priorities, HealthPartners Research Foundation has created Partnership Grants for its parent managed care organization, HealthPartners. Partnership Grants are internal grants designed to answer questions about high-priority programs and patient care issues for the organization by fostering partnerships between researchers and operational leaders. Researchers and operational leaders work together to study how the HealthPartners enterprise might improve the delivery or administration of health care. Applicants are required to show that the proposal represents a real partnership between researchers and operational leaders, and they must include both clear plans for implementation of research findings and an operational leader's commitment to use the plans.

\section{Principle 5. Level of Funding for Implemen- tation Research Is Commensurate With and Proportional to the Magnitude of the Task} Although the Agency for Healthcare Research and Quality is committed to funding PBRNs ${ }^{34}$, the agency budget is only $0.3 \%$ of the investment in health sciences discovery and development in the United States. ${ }^{35}$ The CTSA program may help alleviate some funding shortfall for implementation research, but the total pool of money for CTSAs is small relative to the more than $\$ 111$ billion spent on health research and development in the United States in 2005. ${ }^{35}$ Without adequate funding, innovation in clinical practice to improve patient outcomes cannot be expected to proceed

In conclusion, we recognize that broadening the health sciences research agenda and changing the process by which scarce resources are allocated will not be easy; it will require nothing less than changing the culture of health sciences research. Basic scientists, epidemiologists, and clinicians will need to share the power to set agendas and allocate scarce resources.

The conditions are otherwise ripe for quantum improvements in clinical outcomes, however. The expectations of patients and purchasers of health care are creating pressure for accountability and care improvement. When medical records are designed appropriately, they create the opportunity to rapidly assess gaps in care, variations in care, efforts to improve care, and patient-centered outcomes. A large 
cadre of clinicians seeks to participate in research endeavors and has the interest and ability to develop, test, and implement innovative service and accountability systems to meet these expectations. If reframing the task as optimizing practice through research maintains focus on the target of extending healthy life and reducing the burdens of illness and disability, and if the 5 principles described in this essay are followed, we believe that the sought-after revolution in health care improvement will occur.

\section{To read or post commentaries in response to this article, see it} online at http://www.annfammed.org/cgi/content/full/6/5/459.

Key words: Research; translation; practice

Submitted October 20, 2007; submitted, revised, February 16, 2008; accepted February 25, 2008

Funding support: This report was supported in part by an Agency for Healthcare Research and Quality small conference grant.

Disclaimer: The views expressed in this article are solely those of the authors.

\section{References}

1. Committee on Quality Health Care in America. Institute of Medicine. Crossing the Quality Chasm: A New Health System for the 21st Century. Washington, DC: National Academy Press; 2001.

2. Office of Portfolio Analysis and Strategic Initiatives. National Institutes of Health. NIH Roadmap for Medical Research. http://nihroadmap.nih.gov/overview.asp. Accessed Aug 3, 2007.

3. National Center for Research Resources. National Institutes of Health Department of Health and Human Services. Clinical and Translational Science Awards. http://www.ncrr.nih.gov/clinical_research_resources/ clinical_and_translational_science_awards/. Accessed Aug 1, 2007.

4. Translating Research Into Practice (TRIP). http://www.ahrq.gov/ RESEARCH/trip2fac.htm. Accessed Jun 11, 2008.

5. National Institutes of Health. About NIH. December 14, 2007. http:// www.nih.gov/about/index.html\#mission. Accessed Feb 10, 2008.

6. Sung NS, Crowley WF Jr, Genel M, et al. Central challenges facing the national clinical research enterprise. JAMA. 2003;289(10):1278-1287.

7. Lenfant C. Shattuck lecture-clinical research to clinical practicelost in translation? N Engl J Med. 2003;349(9):868-874.

8. American Heart Association. Heart Disease and Stroke Statistics-2007 Update. Dallas, TX: American Heart Association; 2007.

9. Nishimura RA, Holmes DR, Jr. Clinical practice. Hypertrophic obstructive cardiomyopathy. N Engl J Med. 2004;350(13):1320-1327.

10. Kottke TE, Brekke MJ, Brekke LN, et al. The CardioVision 2020 baseline community report card. Mayo Clin Proc. 2000;75(11): 1153-1159.

11. Daviglus ML, Stamler J, Pirzada A, et al. Favorable cardiovascular risk profile in young women and long-term risk of cardiovascular and all-cause mortality. JAMA. 2004;292(13):1588-1592.

12. Daviglus ML, Liu K, Greenland $P$, et al. Benefit of a favorable cardiovascular risk-factor profile in middle age with respect to Medicare costs. N Engl J Med. 1998;339(16):1122-1129.

13. Khaw K-T, Wareham N, Bingham S, Welch A, Luben R, Day N. Combined impact of health behaviours and mortality in men and women: The EPIC-Norfolk Prospective Population Study. PLoS Medicine. 2008;5(1):e12.
14. Chiuve SE, McCullough ML, Sacks FM, Rimm EB. Healthy lifestyle factors in the primary prevention of coronary heart disease among men: benefits among users and nonusers of lipid-lowering and antihypertensive medications. Circulation. 2006;114(2):160-167.

15. Puska P. Ways Forward and Capacity Building for Better Convergence Between Health, Economy and Culture Along Local and Global Food Chains. November 11, 2007. McGill University. http://www.mcgill. ca/healthchallenge/2007/presentations/opening/. Accessed Dec 28, 2007.

16. Laatikainen T, Critchley J, Vartiainen E, Salomaa V, Ketonen M, Capewell S. Explaining the decline in coronary heart disease mortality in Finland between 1982 and 1997. Am J Epidemiol. 2005;162(8):764-773.

17. Wangensteen $O$, Wangensteen $S$. The Rise of Surgery. From Empiric Craft to Scientific Discipline. Minneapolis, MN: University of Minnesota Press; 1978:357, 474-496.

18. Pronovost $P$, Needham D, Berenholtz $S$, et al. An intervention to decrease catheter-related bloodstream infections in the ICU. N Engl J Med. 2006;355(26):2725-2732.

19. Bodenheimer T, Wagner EH, Grumbach K. Improving primary care for patients with chronic illness. JAMA. 2002;288(14):1775-1779.

20. Bodenheimer T, Wagner EH, Grumbach K. Improving primary care for patients with chronic illness: the chronic care model, Part 2. JAMA. 2002;288(15):1909-1914.

21. Wu AW, Lipshutz AK, Pronovost PJ. Effectiveness and efficiency of root cause analysis in medicine. JAMA. 2008;299(6):685-687.

22. Dash P. Increasing the Impact of Health Services Research on Health Services Improvement: A Report for The Health Foundation \& the Nuffield Trust. London: Health Foundation, Nuffield Trust; 2003.

23. Owen N, Glanz K, Sallis J, Kelder S. Evidence-based approaches to dissemination and diffusion of physical activity interventions. Am J Prev Med. 2006;31(4 Suppl):S35-S44.

24. Ballard DJ, Nicewander DA, Qin H, Fullerton C, Winter FD Jr, Couch CE. Improving delivery of clinical preventive services a multi-year journey. Am J Prev Med. 2007;33(6):492-497.

25. Westfall JM, Mold J, Fagnan L. Practice-based research-"Blue Highways" on the NIH roadmap. JAMA. 2007;297(4):403-406.

26. Tierney WM, Oppenheimer CC, Hudson BL, et al. A national survey of primary care practice-based research networks. Ann Fam Med. 2007;5(3):242-250

27. Green LW. The prevention research centers as models of practicebased evidence two decades on. Am J Prev Med. 2007;33(1 Suppl): S6-58.

28. Van De Ven A, Johnson P. Knowledge for theory and practice. Acad Manage Rev. 2006;31(4):802-821.

29. Batalden PB, Davidoff F. What is "quality improvement" and how can it transform healthcare? Qual Saf Health Care. 2007;16(1):2-3.

30. Lomas J. Health services research. BMJ. 2003;327(7427):1301-1302.

31. McQueen L, Mittman BS, Demakis JG. Overview of the Veterans Health Administration (VHA) Quality Enhancement Research Initiative (QUERI). J Am Med Inform Assoc. 2004;11(5):339-343.

32. Francis J, Perlin JB. Improving performance through knowledge translation in the Veterans Health Administration. J Contin Educ Health Prof. 2006;26(1):63-71.

33. Canadian Health Services Research Foundation. 2006 CHSRF Grants Competition. Research, Exchange \& Impact for System Support (REISS). http://www.chsrf.ca/funding_opportunities/reiss/pdf/2006-call_e.pdf. Accessed Jul 17, 2006.

34. Green LA, Hickner J. A short history of primary care practice-based research networks: from concept to essential research laboratories. J Am Board Fam Med. 2006;19(1):1-10.

35. Hampton T. Health research funding losing ground. JAMA. 2006;296(10):1219-1220 